\title{
O uso de tecnologias digitais em museus de arte o caso do Museo Nacional Centro de Arte Reina Sofía: repensar Guernica
}

\author{
Patricia Lira \\ Universidade de São Paulo, Escola de Comunicação e Artes, Programa de Pós-Graduação em Ciência da \\ Informação, São Paulo, SP, Brasil \\ patricialira@usp.br \\ Giovana Deliberali Maimone \\ Universidade de São Paulo, Escola de Comunicação e Artes, Programa de Pós-Graduação em Ciência da \\ Informação, São Paulo, SP, Brasil \\ gdmaimone@usp.br
}

DOI: https://doi.org/10.26512/rici.v13.n1.2020.29502

Recebido/Recibido/Received: 2020-01-04

Aceitado/Aceptado/Accepted: 2020-03-05

Resumo:O Museo Nacional Centro de Arte Reina Sofía (Madrid, Espanha) reconhecidamente utiliza de tecnologias digitais para promover o acesso e a difusão de suas coleções. Este trabalho apresenta um projeto específico do Museu:Repensar Guernica, website que por meio da conjunção dos processos que fundamentam o museu e o arquivo agrega o máximo de informação disponível sobre a obra Guernica de Pablo Picasso. O objetivo da plataforma é atingir um público amplo, de especialistas em História da Arte aos mais diversos interessados no tema. A partir do estudo de caso do Repensar Guernica demonstramos como a utilização de ferramentas digitais, como exposições virtuais, catálogos online e portais, baseadas na web,é de fundamental importância para a ampliação e a democratização do acesso aos acervos de museus e arquivos. A metodologia emprega a revisão bibliográfica sobre tecnologias digitais aplicadas aos museus e tem em vista algumas temáticas discutidas pelas Humanidades Digitais, como o impacto da tecnologia na organização e preservação de fontes tradicionais de pesquisa.

Palavras-chave: tecnologias digitais. museu de arte. humanidades digitais. Museo Nacional Centro de Arte Reina Sofía.

The use of digital technologies in art museums the case of the Museo Nacional Centro de Arte Reina Sofía: rethinking Guernica

Abstract: The Museo Nacional Centro de Arte Reina Sofía (Madrid, Spain) admittedly uses digital technologies to foster access and diffusion of its collections. This paper presents a specific project from the Museum: Repensar Guernica, website that, through the conjunction of the processes that underlie the museum and the archive, adds as much information as possible about the Pablo Picasso's masterpiece Guernica. The platform goal is to achieve a general audience, from Art History specialists to more varied curious about the subject. As of the Repensar Guernica case study, we prove how digital tools, as virtual exhibitions, online catalogs, and portals, are fundamental to improve and to democratize access for museum collections and archives. The methodology uses the bibliographical review about the digital technologies in the museums and has in mind some issues from the Digital Humanities, like the impact caused by the technology on the preservation of traditional sources of research. 
Keywords: digital technologies. Art museum. digital humanities. Museo Nacional Centro de Arte Reina Sofía.

\section{El uso de las tecnologías digitales en los museos de arte, el caso del Museo Nacional Centro de Arte Reina Sofía: repensar Guernica}

Resumen: Se sabe que el Museo Nacional Centro de Arte Reina Sofía (Madrid, España) utiliza tecnologías digitales para promover el acceso y la difusión de sus colecciones. Este trabajo presenta un proyecto específico del Museo: Repensar Guernica, un sitio web que, combinando los procesos que apoyan el museo y el archivo, agrega la máxima cantidad de información disponible sobre el trabajo Guernica de Pablo Picasso. El objetivo de la plataforma es llegar a un público amplio, desde especialistas en Historia del Arte hasta los más diversos interesados en el tema. Del estudio de caso de Repensar Guernica demostramos cómo el uso de herramientas digitales, como exposiciones virtuales, catálogos en línea y portales basados en la web, es de fundamental importancia para la expansión y democratización del acceso a colecciones de museos y archivos. La metodología utiliza una revisión bibliográfica sobre tecnologías digitales aplicadas a museos y tiene en mente algunos temas discutidos por Humanidades Digitales, como el impacto de la tecnología en la organización y preservación de las fuentes de investigación tradicionales.

Palabras-clave: tecnologías digitales. museo de arte. humanidades digitales. Museo Nacional Centro de Arte Reina Sofía.

\section{Introdução}

Este trabalho parte do princípio de que a informatização e a digitalização ainda em curso nos museus de arte atingiram não só a materialidade dos acervos, que ganharam representantes digitais, isto é, imagens produzidas a partir de processos de digitalização, como também os meios e as ferramentas de trabalho utilizados para a documentação e a conservação desses acervos. Consideramos ainda que tanto as coleções como os arquivos dos museus são importantes fontes primárias para o desenvolvimento de pesquisas em diversos campos, porém essas pesquisas só ocorrem se tais acervos estiverem disponíveis e abertos aos pesquisadores. É neste ponto que localizamos a importância da informatização para a difusão e o acesso às coleções e aos arquivos de museus de arte, tendo em vista o crescente desenvolvimento de projetos atuantes fora dos limites físicos dos museus que objetivam disponibilizar por meio da web, de forma aberta e gratuita, as obras e documentos que formam tais acervos.

Por meio da revisão bibliográfica explicitamos como as Humanidades Digitais discutem as alterações provocadas pela tecnologia da informação na organização, preservação e disponibilização de fontes de pesquisa. Apontamos também como a informatização transformou os processos de preservação e comunicação dos acervos museológicos.

Como estudo de caso apresentamos o projeto desenvolvido pelo Museo Nacional Centro de Arte Reina Sofía, Repensar Guernica. A obra Guernica(1937) de Pablo Picasso foi 
durante certo período uma obra itinerante. O percurso da obra por diferentes instituições e países possibilitou o acúmulo de documentos sobre Guernica em diversas instituições. Hoje grande parte desses documentos pode ser acessada em uma única plataforma online, a Repensar Guernica. A escolha desse projeto como estudo de caso baseou-se nos seguintes aspectos: seu acesso é realizado exclusivamente por meio da web; seus conteúdos possuem relevância para as pesquisas em história da arte; é um projeto de comprovada qualidade técnica; trabalha com a intersecção entre museu e arquivo.

Os resultados do estudo de caso indicam que o projeto Repensar Guernica atende às expectativas quanto à comunicação de diferentes aspectos da obra a um público amplo, e também explicitam a importância do trabalho em rede e da integração entre museus e arquivos. Porém, constatamos que ainda há entraves para usos dos acervos disponibilizados que não se restrinjam à consulta.

\section{Metodologia}

A metodologia utiliza a revisão bibliográfica sobre o uso das tecnologias digitais pelos museus e tem em vista algumas temáticas discutidas pelas Humanidades Digitais, como o impacto da tecnologia na organização, preservação e disponibilização de fontes tradicionais de pesquisa.

A análise do projeto Repensar Guernica foi realizada a partir da navegação detalhada pelo website. Por meio da navegação buscou-se entender como o projeto atende às questões colocadas pela literatura consultada, em especial: trata-se de uma ferramenta voltada para a produção e o compartilhamento do conhecimento?Utiliza recursos digitais para a preservação e comunicação de acervos?Possibilita a utilização dos acervos disponibilizados para fins de pesquisa? É possível o uso desses acervos para outros fins?

\section{Revisão da literatura}

A literatura consultada foi de fundamental importância para o trabalho, pois, além de fornecer as bases teóricas e conceituais sobre os temas abordados, a bibliografia fundamentou as questões utilizadas como recurso metodológico da pesquisa. Foram abordados dois temas: as Humanidades Digitais (HD) e a relação entre acervos de museus e tecnologias digitais para disponibilização e comunicação do material.

\subsection{O campo transdisciplinar das Humanidades Digitais e seus desdobramentos}

Em 2010 um grupo de pesquisadores e intelectuais reuniu-se em Paris na conferência 
ThatCamp - The Humanities and Technology Camp. Dessa conferência resultou a publicação em 2011, com atualização em 2012, do Manifesto das Humanidades Digitais, documento ainda hoje referenciado para a compreensão dos fundamentos e dos objetivos das Humanidades Digitais. Como afirma Pimenta (2016) o campo das Humanidades Digitais já estava em atividade desde o início dos anos 2000, cabendo ao Manifesto, e a conferência que lhe deu origem, o papel de expor a identidade das Humanidades Digitais à comunidade científica. Isto posto, o Manifesto define as Humanidades Digitais como "uma transdisciplina, portadora dos métodos, dos dispositivos e das perspectivas heurísticas ligadas ao digital no domínio das Ciências humanas e sociais" (THATCAMP, 2012).

Ao explicitar a importância da aproximação entre a Ciência da Informação e as Humanidades Digitais (HD), Pimenta (2016) explora a definição do campo das Humanidades Digitais e afirma que elas se configuram "como uma espécie de campo híbrido não apenas de estudo e pesquisa, mas de ensino e, principalmente de acesso à informação e inovação" (PIMENTA, 2016, p. 22). Para mais, as Humanidades Digitais se caracterizam pela autorreflexão, isto é, a aplicação da tecnologia pelas humanidades é ela própria objeto de estudo das HD (Ibid., 2016).

Em Almeida e Damian (2015) encontramos a constatação de que "cultura e tecnologia associadas tornam-se centrais na dinâmica das sociedades contemporâneas"' (ALMEIDA; DAMIAN, 2015 , n.p.), fato que para os autores gera implicações nas maneiras pelas quais a sociedade e os indivíduos se relacionam com o montante de informação gerado constantemente pela denominada "sociedade da informação". Almeida e Damian (2015) apontam para a necessidade de apropriação da informação, ação que ultrapassa o acesso, para tanto, são necessárias competências tanto tecnológicas quanto culturais, para que o indivíduo possa contextualizar o que se produz no meio informacional e utilizá-lo de forma crítica e com aplicações sociais. As Humanidades Digitais, conforme propõem Almeida e Damian (2015), seria o campo agregador das discussões acerca da produção informacional e de sua circulação e apropriação social.

Inserida na discussão e nos propósitos das Humanidades Digitais encontra-se a história digital.A história digital envolve tanto o uso de ferramentas digitais para a realização da pesquisa histórica, quanto à utilização de plataformas, também digitais, para o compartilhamento do processo e dos resultados das pesquisas. Como ferramentas digitais para pesquisa entendem-se tanto o uso de documentos digitalizados como fonte primária, como o domínio da recuperação da informação em bases de dados, o uso de diferentes softwares para o tratamento de dados coletados, e, em certa medida, a compreensão das linguagens de programação. Ademais, a história digital também pode ser discutida no contexto epistemológico da História enquanto 
disciplina. Alguns pesquisadores, entusiastas da história digital, estão se debruçando sobre o uso da tecnologia na pesquisa histórica, destacamos aqui Noiret (2015) e Telles (2017).

Serge Noiret (2015) indaga se estaria em produção uma história digital ou "uma história por meios digitais" (NOIRET, 2015, p. 29). Nesse sentido, o autor afirma que há uma mudança em curso no trabalho do historiador, tal mudança obriga o historiador a dominar os meios digitais de tal modo que os pesquisadores encontram-se confusos e temerosos frente à "virada digital", e confrontam-se com o fato de que a simples utilização de um computador não é praticar história digital. A história digital é definida por Noiret como a utilização de ferramentas digitais, em rede, em todas as etapas da pesquisa, isto é, da delimitação da hipótese ao acesso às fontes, da execução da pesquisa à sua comunicação. $O$ próprio ensino da História também é atravessado pela "cultura histórica digital" que "é parte de uma cultura digital mais vasta que permeia a nossa sociedade por meio da internet e sob várias formas comunicativas" (Ibid., p.31).

Ainda segundo Noiret devem ser observadas as particularidades da história digital, que dizem respeito à visualização das narrativas históricas "não apenas e essencialmente baseadas no texto" (Ibid., p. 32) e à capacidade que a história digital possui de "modificar os parâmetros da pesquisa." (Ibid., p. 33). O autor coloca ainda que a História e a Historiografia são e serão digitais, mesmo se os historiadores não dominarem os instrumentos dessa História ou não forem capazes de lidar com programas específicos para a análise histórica.

Além de a história ter se tornado digital, ela também é pública, ou melhor, a história digital, como explica Noiret facilita o acesso público às fontes históricas e promove a publicização de narrativas históricas, coletivas ou individuais, narrativas essas que necessariamente demandam a interpretação e a mediação do historiador profissional para não se tornarem falácias ou mesmo revisionismo histórico (NOIRET, 2015). Encontramos em Noiret a defesa da mudança do status da história diante da sociedade, já que as fontes para a pesquisa histórica estão em processo de digitalização e de disponibilização online, tal fato "corroeu a férrea distinção que um dia existiu entre a pesquisa acadêmica e as práticas públicas relativas ao passado (...)" (NOIRET, 2015, p. 34). Para o autor, o advento da web2.0 agregou ao acesso aberto das fontes a possibilidade de desenvolvimento de pesquisas colaborativas, que seria outro aspecto da história pública digital.

Telles (2017) reitera o pensamento exposto por Noiret ao afirmar que as humanidades digitais e, em consequência, a história digital, estão preocupadas com a produção do conhecimento assim como com o "acesso e a difusão do conhecimento através das plataformas digitais." (TELLES, 2017, p. 83). O autor também aponta as alterações nos métodos de pesquisa das áreas relacionadas às ciências sociais e humanas como um fator a ser considerado na emergência das humanidades digitais e da história digital, dentre essas alterações está a 
ampliação do público capaz de acessar os resultados dos projetos e a colaboração entre pares, acadêmicos ou não, na produção de pesquisas (TELLES, 2017).

Ao tratar das questões que envolvem a epistemologia da história, Telles, coloca a história digital no contexto "das mudanças que tiveram lugar no campo historiográfico após a Segunda Guerra Mundial" (Ibid., p. 86), o que significa que, assim como em outras áreas do conhecimento, as transformações na maneira de coletar fontes, desenvolver e disseminar pesquisas iniciou-se em meados dos anos 1940 e acompanhou a evolução tecnológica até os dias atuais. A difusão de fontes primárias propiciada pela história digital é encarada positivamente por Telles, além disso, o pesquisador afirma que o contexto no qual se encontra a produção histórica possibilita a conexão de narrativas de diferentes grupos sociais e o reconhecimento de dados até então pouco explorados pelos historiadores. Para Telles "essa posição pode contribuir para repensar a prática e o valor da História para a sociedade contemporânea, além de recuperar a dimensão ética do conhecimento histórico." (ibid.,p. 89).

Porém, para atingir todas as potencialidades da história digital descritas por Telles (2017) e Noiret (2015), os historiadores têm como obstáculo a ausência de capacidade técnica para acessar e refinar a enorme quantidade de dados disponível online. Sobre esse ponto Telles afirma que os métodos da pesquisa histórica ainda seguem os padrões tradicionais devido ao pouco domínio que os historiadores possuem sobre determinadas ferramentas digitais.

Um contraponto aos argumentos defendidos por Noiret (2015) e Telles (2017) pode ser encontrado no artigo de Câmara e Benício (2017) que busca analisar o que os pesquisadores acreditam ser as armadilhas da história digital. Os autores contextualizam a história digital na sociedade em rede, e afirmam que tal sociedade ainda vive sob a promessa da democratização do acesso à informação e ao conhecimento; a história digital faria parte dessa expectativa, já que um de seus principais traços diz respeito justamente à produção e à disseminação do conhecimento em rede. Porém, Câmara e Benício apontam que ainda há alguns desafios a serem ultrapassados para que essa promessa se concretize, e o principal deles seria a superação dos filtros que direcionam o pesquisador - e os indivíduos de maneira geral - em sua busca por dados e informação confiáveis:

Além de enfraquecer nosso senso do que é público, que se baseia, essencialmente, em questões que nos são alheias, a personalização da internet leva o usuário a um sentimento da infalibilidade, uma vez que sua percepção de mundo está deformada pelos filtros. Sem saber quais os critérios de seleção são utilizados para definir o que será tornado visível e o que será deixado de fora, o indivíduo tem a sensação de que está vendo tudo, e de que tudo corresponde ao modo como ele pensa. (CÂMARA; BENÍ́CIO, 2017, p. 48).

Tendo em vista a inserção da tecnologia digital nos estudos do campo da história da arte, a pesquisa desenvolvida em conjunto pela Samuel H. Kress Foundation, Roy Rosenzweig Center 
for History and New Media e George Mason University, e relatada por Diane Zorich (2012), também apresenta um panorama não muito otimista. As três instituições focaram-se nos centros de pesquisa em história da arte e procuraram entender, dentre outros pontos: como esses centros se relacionam com as humanidades digitais e com a história digital; quais são os desafios colocados pelos ambientes digitais à pesquisa e ao ensino da história da arte; como se apresentam as formas de acesso às ferramentas digitais necessários à pesquisa; e qual seria o papel das publicações em formato digital (ZORICH, 2012).

O resultado de tais indagações, apontado por Zorich, indica que a comunidade envolvida nas pesquisas de história da arte acredita no potencial que os ambientes digitais possuem em favorecer o acesso ao resultado das pesquisas, porém são céticos quanto à influência que esse mesmo ambiente possa ter no desenvolvimento dos projetos, ou mesmo na maneira como se realiza a pesquisa em história da arte (Ibid.).

\subsection{Museus e tecnologia digital}

Os museus contemporâneos, segundo Castells (2011), atuam como "conectores culturais", pois possuem a capacidade de intervir na "contradição cultural atual" que se exprime pela existência de uma sociedade em rede em contraponto a uma ruptura da comunicação individual (CASTELLS, 2011, p. 9). Castells desenvolve sua argumentação colocando que a comunicação em nossa sociedade atual é hipertextual, no sentido de fragmentária, e que esse hipertexto é construído no âmbito individual, e não no coletivo. Soma-se a isso "a individualização generalizada das nossas vidas, das práticas sociais e do nosso trabalho" (Ibid., p. 12). Como resposta a tal situação, Castells propõe os "protocolos de comunicação cultural”, que seriam manifestações que possuem a capacidade de criar pontes entre uma cultura e outra. Para Castells a arte sempre foi, e ainda é, um "protocolo de comunicação cultural" que possui a capacidade de ser um instrumento de reconstrução social (Ibid., p. 13).

Esses mesmos museus, devido à característica de abrigar diversas temporalidades construídas pelos indivíduos e pela história humana e por se configurarem como espaços essencialmente públicos, também teriam a capacidade de atuar como "protocolos de comunicação cultural”:

Nesse contexto, os museus poderiam tornar-se protocolos de comunicação entre diferentes identidades, comunicando a arte, a ciência e a experiência humana; e eles podem estabelecer-se como conectores de diferentes temporalidades, traduzindo-as a uma sincronia comum, mantendo, ao mesmo tempo, uma perspectiva histórica. Finalmente, eles podem conectar as dimensões globais e locais de identidade, espaço e sociedade local (CASTELLS, 2011, p. 20). 
Para não correr o risco de serem transformados em "mausoléus de cultura histórica reservados para o prazer de uma elite global" (Ibid., p. 21), e para cumprir seu papel de conector cultural junto à sociedade, Castells afirma que os museus precisarão articular arte, experiência humana e tecnologia.

No que diz respeito à tecnologia, sua utilização nos museus não é um fato recente.A informatização dos museus, assim como a informatização das mais diversas instituições da sociedade contemporânea, iniciou-se com a introdução de programas computacionais, e do próprio uso dos computadores, no auxílio aos profissionais de tais instituições em suas atividades cotidianas. Com o passar das últimas décadas, os museus apropriaram-se da tecnologia digital e passaram a empregá-la de maneira mais efetiva nas ações de preservação, entendidas pela museologia como "todas as ações envolvidas quando um objeto entra no museu, isto é, todas as operações de aquisição, entrada de inventário, catalogação, acondicionamento, conservação e restauração" (DESVALLÉES; MAIRESSE, 2013, p. 79) e de comunicação - difusão por meio de exposições, catálogos, artigos ou disponibilização dos acervos, e de suas informações associadas, para acesso público (DESVALLÉES; MAIRESSE, 2013, p. 35). Dessa maneira, a informatização dos museus pode ser encontrada em diversos recursos; das ferramentas para a elaboração de listas de inventário às avançadas tecnologias utilizadas em visitas virtuais.

Como se verá adiante, a literatura sobre o tema - museus e tecnologias digitais - discorre justamente sobre os processos afetados pela introdução da tecnologia digital nas instituições museológicas. Para os autores consultados ocorreram alterações significativas nas práticas de catalogação, gestão, conservação e comunicação das coleções em salvaguarda nos museus, tais alterações caracterizam-se pela utilização de banco de dados, automação de procedimentos de conservação, digitalização de acervos e disponibilização de obras digitalizadas via internet.

A utilização de banco de dados na organização, descrição, indexação e gestão de coleções é identificada por Magalhães (2014) e Dodebei (2017) como o elemento que introduziu as tecnologias digitais nos museus. Dodebei (2017) afirma que "o primeiro momento de informatização dos museus, por exemplo, pode ser considerado aquele no qual foram desenvolvidos bancos de dados para registrar/inventariar coleções de peças adquiridas" (DODEBEI, 2017, p. 82).

Já Magalhães (2014) identifica os bancos de dados como a ferramenta que impulsionou a documentação "historicizada" das obras, pois possibilita o registro de dados técnicos e administrativos, mas também informações sobre o contexto de criação das obras e "dos fluxos de atividades dentro do museu, registrando seus deslocamentos, condições e tratamentos em uma complexa rede de informações" (MAGALHÃES, 2014, p. 35). 
Atualmente, os bancos de dados de acervos museológicos, muitos deles desenvolvidos a partir de softwares criados para o gerenciamento de conteúdo localizado na $w e b^{1}$, tendem a oferecer funcionalidades que propiciam não apenas o registro e a descrição das obras, como também são capazes de estruturar instrumentos de pesquisa e de difusão virtuais dos acervos, como catálogos, exposições e visitas. Dessa forma, é possível obter, com a utilização de uma só ferramenta, os meios necessários para o desenvolvimento de algumas das atividades que fundamentam os museus.

Deve-se ter claro, contudo, que as práticas envolvidas nos processos de documentação de acervos museológicos ${ }^{2}$ não se modificam em si com a introdução e desenvolvimento dos bancos de dados, estando eles baseados na web ou não. O registro sistematizado das peças que formam um acervo, assim como sua descrição e indexação, seguem princípios não-dependentes e anteriores à informatização dos museus. A modificação se dá, principalmente, na aplicação de tais princípios e nas múltiplas possibilidades de conexão entre os dados registrados nesses bancos.

A conservação dos acervos museológicos, entendida como os procedimentos preventivos e curativos "necessários para garantir o estado de um objeto contra toda forma de alteração, a fim de mantê-lo o mais intacto possível para as gerações futuras" (DEVALLÉES; MAIRESSE, 2013, p. 80) também passou por transformações com a inserção das tecnologias digitais. Essas tecnologias são encontradas em softwares utilizados na identificação de materiais e processos de deterioração, no controle ambiental de reservas técnicas, na automação de dispositivos de segurança contra incêndios e em sistemas de gestão voltados para a conservação, por exemplo.

A tecnologia influencia não apenas a preservação das obras de arte, como também a própria produção artística. Vellosillo (2014) ao analisar a influência que a tecnologia exerceu sobre a arte ao longo da história, especialmente nos períodos moderno e contemporâneo, explora o desafio que os materiais utilizados pelos artistas trouxeram à conservação das obras:

As coleções tecnológicas impõem novos desafios à conservação de obras realizadas em suportes e formatos em contínua evolução. A sobreposição de meios, ferramentas, estilos, formas e ideias dificultam uma leitura linear

\footnotetext{
${ }^{1}$ Como exemplos, citamos o Museum Plus, sistema de gerenciamento de coleções museológicas baseado na web desenvolvido pela empresa suíça Zetcom:

Disponível em: <http://www.zetcom.com/en/museumplus en/>. Acesso em: 29 de out. 2019.

$\mathrm{O}$ inPatrimonium, um dos produtos voltados para a gestão do patrimônio cultural criado pela portuguesa Sistemas do Futuro. Disponível em:<http://sistemasfuturo.pt/>. Acesso em: 29 de out. 2019.

O Drupal, sistema de gerenciamento de conteúdo web com código aberto. Disponível em: <https://www.drupal.org/>. Acesso em: 29 de out. 2019.

O SharePoint, sistema proprietário de gerenciamento de conteúdo web da Microsoft. Disponível em: <https://www.innovativearchitects.com/microsoft-cms.aspx>. Aceso em: 29 de out. 2019.

2 "A documentação museológica tem como particularidade reconhecer os acervos museológicos, independentemente de sua natureza, como suportes de informação. Está focada na busca, reunião, organização, preservação e disponibilização de todas as informações, sobre quaisquer suportes, que digam respeito a esses mesmos acervos" (BOTALLO, 2010, p. 51).
} 
dessas obras e a aplicação de protocolos padronizados para analisar, compreender, conservar e expor um grande número de propostas atuais. Isso dificulta a gestão das coleções e a criação e aplicação de protocolos de atuação. A evolução vertiginosa da tecnologia e o modo de uso desses recursos por parte dos artistas muitas vezes supera a capacidade de museus e coleções. (VELLOSILLO, 2014, p. 138).

Para a autora, a resposta a esse desafio, estaria no emprego de ferramentas digitais não somente nos procedimentos de conservação, como também para fomentar e facilitar a colaboração entre os profissionais que lidam com tais obras (VELLOSILLO, 2014, p. 140).

Aliada aos recursos dos bancos de dados e das técnicas desenvolvidas para a conservação física dos acervos está a digitalização - processo de conversão dos suportes analógicos para os digitais, realizado por meio de uma infraestrutura de captura e conversão, onde o sinal ou a imagem analógicos transformam-se em cadeias de bits, cadeias essas que podem ser processadas e armazenadas por computadores. A digitalização de acervos relacionase com diversas atividades da cadeia de preservação: ela facilita a pesquisa e colabora com a catalogação ao propiciar um contato mais amplo e seguro com a obra analisada; transforma-se em uma ferramenta de gestão ao produzir imagens para inventários e amplia as possibilidades de conservação com a diminuição do manuseio das obras e, no caso dos acervos audiovisuais, a atualização de suportes tecnologicamente obsoletos. Tais atributos da digitalização abrangem prioritariamente os profissionais envolvidos nas atividades de preservação.

Segundo Magalhães (2014) o momento inicial da digitalização de acervos foi acompanhado por uma série de desafios aos museus e seus profissionais. A autora afirma que a falta de experiência em lidar com a obsolescência e com a vulnerabilidade dos formatos digitais proporcionou um alerta às instituições e, de certa forma, as deixou mais bem preparadas para o andamento desse processo, considerado por Magalhães irreversível e contínuo.

Porém, a digitalização de acervos afeta também a relação que se estabelece entre o público e o museu. Tardy (2015), por exemplo, entende que a condição da digitalização de acervos alterou-se significativamente; antes técnica empregada para o inventário e estudo de obras, a digitalização atualmente é um importante instrumento de mediação entre o museu e seu público. Encontramos reflexão semelhante em Padilha; Café e Silva (2014). Os autores tratam da expansão do acesso aos acervos possibilitado especialmente pela disponibilização via internet de acervos digitalizados,e afirmam que as formas de interação entre público e museu foram alteradas pela utilização das tecnologias digitais.

\section{0 caso do Museo Nacional Centro de Arte Reina Sofía e o projeto Repensar Guernica}


$\underline{\text { RepensarGuernica }}^{3}$ é um projeto desenvolvido pelos departamentos de Coleções, Restauração e Conservação e Projetos Digitais do Museo Nacional Centro de Arte Reina Sofía, instituição responsável pela preservação da obra de Pablo Picasso.Trata-se de um website que agrega o máximo de informação disponível sobre a obra. Lançado em 2017 é um projeto em desenvolvimento, já que a coleta de dados, o desenvolvimento de pesquisas, e a digitalização e disponibilização dos documentos relacionados à pintura ainda estão em curso (CON, 2017).

Em um período de dois anos foram analisados mais de seis mil documentos, desses, dois mil encontram-se disponíveis online. Essa documentação é procedente de mais de 120 instituições, públicas e privadas, espanholas ou não, como o Museu Picasso de Paris, o Centro Pompidou, o Arquivo Roland Penrose de Edimburgo e o Arquivo Histórico Nacional espanhol. Os gêneros e as tipologias documentais também são vastos; há fotografias, correspondência, panfletos, vídeos, reportagens, cartazes e catálogos, por exemplo.

O site organiza-se em três seções: Cronología; Itinerarios e Gigapíxel. Há uma página introdutória que narra a história da obra e apresenta o projeto.

Na seção Cronología $a^{4}$ pode-se visualizar o conjunto documental reunido pelo Museu em sua totalidade.O conteúdo dessa seção está ordenado segundo os anos de produção dos documentos, de 1936 a 2019, porém com possibilidades de expansão até 2020, o que reafirma o caráter de arquivo aberto presente no projeto. $\mathrm{O}$ acesso aos documentos dá-se tanto pela divisão cronológica - com atenção ao ano de 1981, que possui o maior número de documentos associados, visto que foi o ano de retorno da obra à Espanha - como por meio da aplicação dos filtros "relatos", "agentes" e "tipo de material". O acesso aos documentos ocorre diretamente pelo website ou por meio de direcionamento aos websites das instituições parceiras do projeto. Nos dois casos os documentos digitalizados apresentam-se íntegros e perfeitamente legíveis, o que atesta a possibilidade de substituição da consulta ao documento original pela consulta ao documento digitalizado. ${ }^{5}$

Em Itinerários ${ }^{6}$ encontramos a organização contextual dos documentos que também pode ser considerada como sugestões temáticas para a navegação. Os temas tratados nessa seção foram determinados pelas pesquisas sobre a obra desenvolvidas pelo Museu.Dessa

\footnotetext{
${ }^{3}$ Disponível em:<https://guernica.museoreinasofia.es/>. Acesso em: 5 nov. 2019.

${ }^{4}$ Disponível em:<https://guernica.museoreinasofia.es/cronologia/>. Acesso em: 5 nov. 2019.

${ }^{5}$ Como exemplos, destacamos: o acesso às Conferencias sobre el siglo XIX y Guernica celebradas dentro del programa Misiones del Arte del Museo Nacional del Prado de mayo a junio de 1982, documento sob a guarda do arquivo do Museo del Prado.Disponível em:<https://guernica.museoreinasofia.es/documento/conferencias-sobreel-siglo-xix-y-guernica-celebradas-dentro-del-programa-misiones-del-arte-del-museo-nacional-del-prado-de-mayojunio-de-1982>; <https://archivo.museodelprado.es/prado/record/1@50386>. Acesso em: 5 nov. 2019; e o acesso à Carta de Daniel-Henry Kahnweiler a Pablo Picasso del 25 de junio de 1954.Disponível em:<https://guernica.museoreinasofia.es/documento/carta-de-daniel-henry-kahnweiler-pablo-picasso-del-25-dejunio-de-1954>. Acesso em: 5 nov. 2019.

${ }^{6}$ Disponível em:<https://guernica.museoreinasofia.es/itinerarios>. Acesso em: 5 nov. 2019.
} 
forma, temos: Geografía sin límites, trata dos deslocamentos de Guernica; El cuadro desjerarquizado, propõe um olhar sobre Guernica para além da própria obra; Debates artísticos, traz parte da fortuna crítica sobre Guernica; Símbolo político, com a dimensão política, passada e atual, da obra; Clave museística, presença de Guernica em diferentes museus;Réplica, trata da transformação do quadro em imagem icônica; Bombardeos, sobre o bombardeio à cidade de Guernica; Guernica según Picasso, a relação de Picasso com os deslocamentos de sua obra; Persistencia del pabellón de 1937, que nos conta sobre o pavilhão espanhol construído para a Exposição Internacional de Paris de 1937, exposição para a qual Guernica foi pintada.

Por sua vez, Gigapíxelp expõe e amplia a materialidade de Guernica. A pintura pode ser visualizada sob a luz visível, ultravioleta, infravermelha, bem como sob técnicas radiográficas. Disponibilizam-se nesta seção informações técnicas sobre o processo de execução, bem como sobre os danos sofridos ao longo do tempo e os processos de restauração empregados na pintura. Também há a possibilidade de acesso pormenorizado a um caderno de estudos técnicos sobre a obra elaborado pelo Departamento de Conservación-Restauración do Museo Reina Sofía ${ }^{8}$. A diferença de Gigapíxel em relação a outras ferramentas de visualização de obras de arte digitalizadas reside no fato de ela não pretender reproduzir a experiência do contato com a obra de arte original. Ao contrário, Gigapíxel oferece outra vivência, realizável somente nos meios digitais.

\section{Conclusões}

O projeto Repensar Guernica comprova a possibilidade de trabalho em rede não só entre museus como entre museus e arquivos. Nesse sentido, esta iniciativa nos convida a refletir sobre a importância da interoperabilidade de dados mantidos por essas instituições, bem como sobre a necessidade de padronização dos processos de digitalização.Trata-se de uma ferramenta de compartilhamento do conhecimento, executada por uma instituição museológica que demonstra com essa iniciativa sua preocupação com a inovação e com o acesso público à sua coleção. Além disso, o projeto insere-se no âmbito do uso da tecnologia digital como meio para a preservação de obras de arte - visto que apresenta as técnicas empregadas para a conservação e restauração da pintura - e como ferramenta de consulta aos acervos que, por sua vez, se apresentam como fontes documentais.

\footnotetext{
7 Disponível em:<https://guernica.museoreinasofia.es/gigapixel/\#3/63.11/-120.59>. Acesso em: 5 nov. 2019.

8 Disponível em:<https://guernica.museoreinasofia.es/gigapixel/informe-estado-conservacion>. Acesso em: 5 nov. 2019.
} 
Finalmente, consideramos que Repensar Guernica também é uma plataforma para a divulgação das pesquisas realizadas pelo próprio Museo Reina Sofía.Entretanto, há dúvidas sobre possibilidades de uso dos documentos disponibilizados que não se restrinjam apenas à consulta, como o educacional,já que há limites legais para a divulgação pública do material digitalizado.

Repensar o museu na sociedade contemporânea é fundamental. O sucesso de exposições interativas não deve ser ignorado e sim utilizado como objeto de reflexão pelos gestores de instituições museológicas e por aqueles que pesquisam e estudam essas instituições. É com a colaboração entre pesquisadores, técnicos e gestores que a interação não se transformará em mero espetáculo, mas sim em catalisadora da produção de conhecimento. Isto posto, consideramos que Repensar Guernica é um projeto que objetiva repensar não apenas uma obra de arte, mas sim toda a cadeia relacional existente entre museu, arquivo, pesquisa e público.

\section{Referências}

ALMEIDA, Marco Antônio de; DAMIAN, leda Pelógia Martins. Humanidades Digitais: um campo praxiológico para mediações e políticas culturais? In: ENCONTRO NACIONAL DE PESQUISA EM CIÊNCIA DA INFORMAÇÃO, 16, João Pessoa: ANCIB, 2015. Anais. n. p. Disponível em: $<$ http://www.ufpb.br/evento/index.php/enancib2015/enancib2015/paper/view/2999>. Acesso em: 29 out. 2019.

BOTALLO, Marilúcia. Diretrizes em Comunicação Museológica. In: Associação Cultural de Amigos do Museu Casa de Portinari. Documentação e Conservação de Acervos Museológicos: diretrizes. Brodowski: Associação Cultural de Amigos do Museu Casa de Portinari; Secretaria de Estado da Cultura de São Paulo, 2010.

CÂMARA, Sérgio Antonio; BENICIO, Milla. História digital: entre as promessas e armadilhas da sociedade informacional. Revista Observatório, v. 3, n. 5, p. 38-56, ago. 2017. Disponível em: $<$ https://sistemas.uft.edu.br/periodicos/index.php/observatorio/article/view/3596>. Acesso em:20 out. 2019.

CON "REPENSAR GUERNICA. HISTORIA Y CONFLICTO DEL SIGLO XX" EL BIG DATA SE VUELVE FUNCIONAL AL ARTE. Revista Digital Nueva Museología. Madrid: 14 nov. 2017. Disponível em: $<$ https://nuevamuseologia.net/con-la-web-repensar-guernica-historia-y-conflicto-del-siglo-xx-elbig-data-entra-de-lleno-en-el-arte/>. Acesso em: 3 nov. 2019.

CASTELLS, Manuel. Os museus na era da informação: conectores culturais de tempo e espaço. Musas: Revista Brasileira de Museologia, Brasília, v. 7, n. 5, p. 8-21, 2011.Disponível em: $<$ https://www.museus.gov.br/wp-content/uploads/2015/01/Revista-Musas-5.pdf $>$. Acesso em: 30 jul. 2018.

DESVALLÉES, André; MAIRESSE, François. Conceitos-chave de Museologia. São Paulo: Comitê Brasileiro do Conselho Internacional de Museus; Pinacoteca do Estado de São Paulo; Secretaria de Estado da Cultura, 2013. 
DODEBEI, Vera. Cultura e patrimônio na era da informação. In: MARINGELI, Cristina Ayres da Silva (org.). IV Seminário Serviços de Informação em Museus: informação digital como patrimônio cultural. São Paulo: Pinacoteca de São Paulo, 2017, p. 81-90.

MAGALHÃES, Ana Gonçalves. Considerações para uma análise histórico-crítica da catalogação de acervos artísticos. In: BEIGUELMAN, Gisele; MAGALHÃES, Ana Gonçalves. Futuros possíveis: Arte, museus e arquivos digitais. São Paulo: Petrópolis, 2014, p. 34-43.

NOIRET, Serge. História pública digital. Liinc em Revista, Rio de Janeiro, v. 11, n. 1, p. 28-51, mai., 2015. Disponível em: < http://revista.ibict.br/liinc> Acesso em: 30 jul. 2018.

PADILHA, Renata Cardozo; CAFÉ, Ligia; SILVA, Edna Lucia da. O papel das instituições museológicas na sociedade da informação/conhecimento. Perspectivas em Ciência da Informação. Belo Horizonte, v. 19, n. 2, p. 68-82, abr./jun. 2014. Disponível em: $<$ http://portaldeperiodicos.eci.ufmg.br/index.php/pci/article/view/1889/1395>. Acesso em: 20 out. 2019.

PIMENTA, Ricardo Medeiros. Os objetos técnicos e seus papéis no horizonte das humanidades digitais: um caso para a Ciência da Informação. Revista Conhecimento em Ação, Rio de Janeiro, v. $1, \quad$ n. 2, jul/dez., p. 20-33, 2016. Disponível em: <https://revistas.ufrj.br/index.php/rca/article/view/20>. Acesso em:20 out. 2019.

TARDY, Cécile. A mediação de autenticidade dos substitutos digitais. In: TARDY, Cécile; DODEBEI, Vera. Memória e novos patrimônios. Marseille: Open Edition Press, 2015.

THATCAMP. Manifesto das humanidades digitais. Paris: ThatCamp [The Humanities and Technology Camp]. 2011. Disponível em: <https://tcp.hypotheses.org/497>. Acesso em: 3 nov. 2019.

TELLES, Helyom Viana. História digital, sociologia digital e humanidades digitais: algumas questões metodológicas. Revista Observatório, v. 3, n. 5, p. 74-101, ago., 2017.Disponível em: $<$ https://sistemas.uft.edu.br/periodicos/index.php/observatorio/article/view/3810 >. Acesso em: 20 out. 2019.

VELLOSILLO, Arianne Vanrel. Estratégias de conservação e humanidades digitais. In: BEIGUELMAN, Gisele; MAGALHÃES, Ana Gonçalves. Futuros possíveis: Arte, museus e arquivos digitais. São Paulo: Petropolis, 2014. p. 135-146.

ZORICH, Diane. Transitioning to a Digital World: Art History, its Research Centers, and Digital Scholarship. Journal of Digital Humanities, Fairfax, v. 1, n. 2, March/May 2012. Disponível em: <http://journalofdigitalhumanities.org/1-2/transitioning-to-a-digital-world-by-diane-zorich/>. Acesso em: 3 nov. 2019. 